\title{
SQUIRREL HOUSE ON THE PRAIRIE
}

\author{
PETER TAYLOR P.O. Box 597, Pinawa, MB, R0E 1 L0
}

Email: taylorp@granite.mb.ca

In the late afternoon of 3 December 2011, Reto Zach and I were birding along Overwater Road, a lightly used gravel road in open cropland east of Stead, Manitoba. We had paused to watch a snowy owl (Bubo scandiacus) when I noticed a red squirrel (Tamiasciurus hudsonicus) at the entrance to a tunnel in a snowdrift near some isolated farm buildings $-\mathrm{a}$ wooden equipment shed and four steel and the nearest forest edge was $3.1 \mathrm{~km}$ to the east.

I revisited the site on 11 December 2011 and saw three red squirrels on or near the equipment shed (Figure 2). Tracks and tunnels in the snow radiated from the shed and were concentrated alongside the 60-metre access trail from the road. There was no evidence that the squirrels had entered the securely

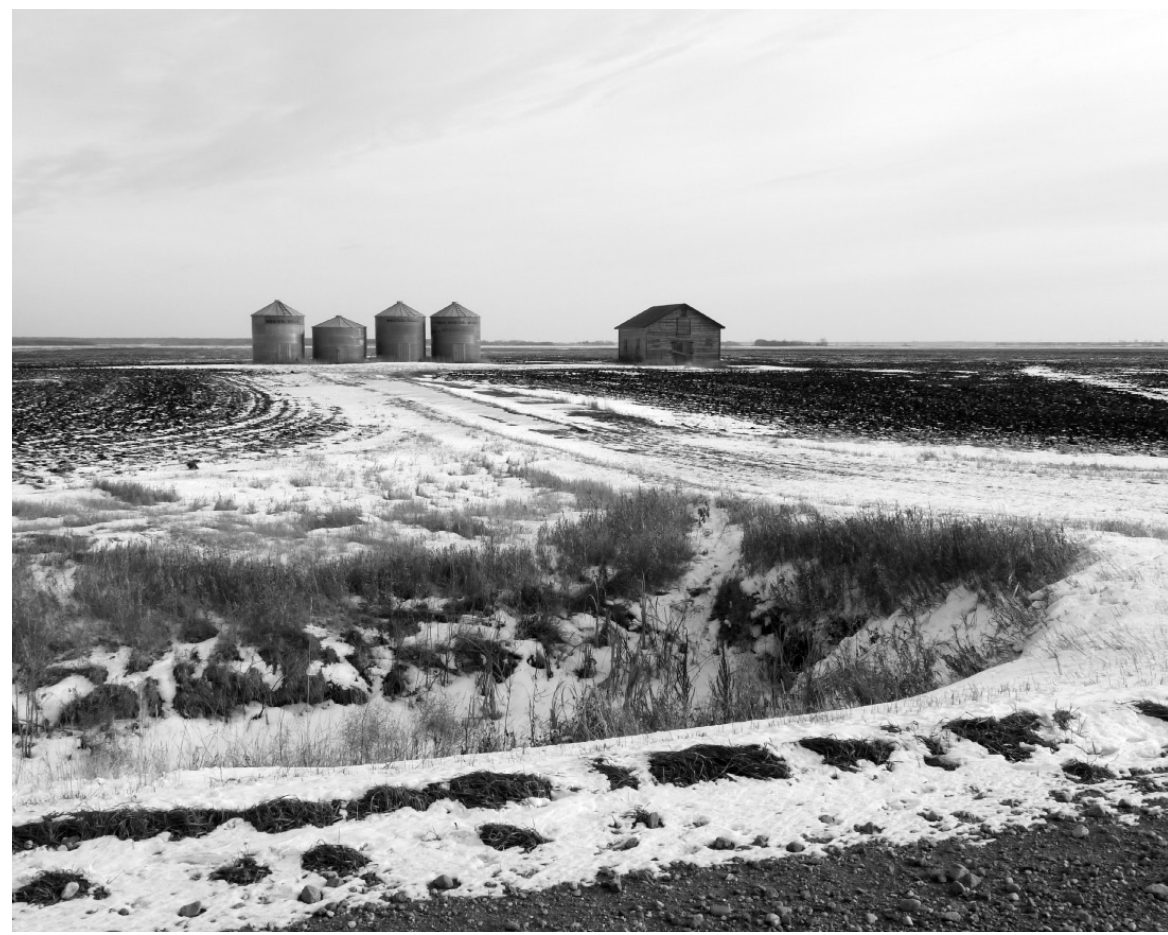

Figure 1: Unusual winter habitat for red squirrels near Stead, Manitoba.

- Peter Taylor

granaries (Figure 1). As we watched, a second squirrel appeared in a window frame on the shed. The location $\left(50.341^{\circ} \mathrm{N}, 96.328^{\circ} \mathrm{W}\right)$ was not typical red squirrel habitat, the nearest sparse shelter belt being $700 \mathrm{~m}$ to the south, closed granaries. Peering through a broken window in the shed, I could see no obvious food supply inside.

One alert squirrel was seen at a snow-tunnel entrance on a third visit on 
8 February 2012, but there was no sign of activity on 18 March 2012, shortly after the unusually early spring thaw. Checking the area where the snow tunnels had been, I found a narrow $(<1 \mathrm{~m}$ wide) strip of unharvested soybeans alongside the access trail. These had evidently been the principal, if not only, food supply for the squirrels.

Based on their seemingly placid coexistence, the squirrels may have been a family group. Their occurrence so far outside forested habitat was possibly related to a poor cone and wild fruit crop the preceding fall. Red squirrels are opportunists, frequently visiting bird feeders and boldly entering attics whenever an opening is available. Nevertheless, their ability to survive for much of the winter at a site meeting the barest requirements of food and shelter in a hostile landscape is remarkable.

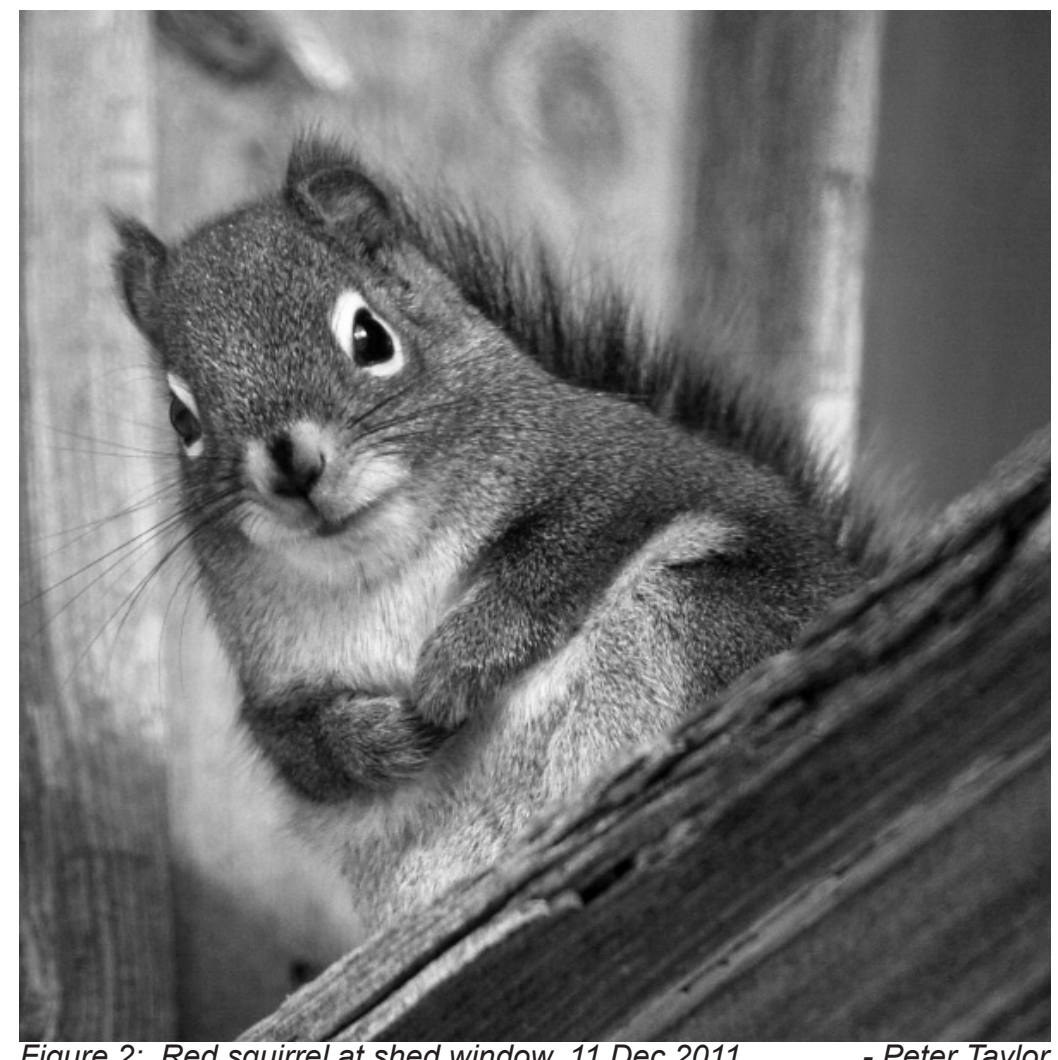

Figure 2: Red squirrel at shed window, 11 Dec 2011.

- Peter Taylor 